\title{
The Cambodians in Sydney
}

\section{Ashley Carruthers}

\section{Sarithya Tuy}

Cambodians began coming to Australian in the mid to late 1970s, predominantly after the fall of the country's genocidal Khmer Rouge regime to invading Vietnamese forces in 1978. The majority fled to Thailand, either overland or by sea, where they waited in refugee camps for resettlement. A large part of the existing community arrived in the 1980s, either as refugees or as family reunion migrants. Today in Sydney there are 8,900 people of Khmer ancestry, and 4,507 of Chinese Cambodian ancestry (out of a national population of 25,553 of Khmer ancestry and 9,667 of Chinese Cambodian background). Over 60 per cent of those of Cambodian background who live in Sydney reside in the Fairfield local government area. ${ }^{1}$ Community life centres on the Khmer temples of Fairfield and Liverpool and the commercial and cultural centre of Cabramatta.

\section{Creating a community}

At the time of the fall of Phnom Penh to the Khmer Rouge in 1975, there was already a small number of Cambodians in Australia studying under the Colombo Plan program, almost all of whom stayed on in Australia. The leaders of the community in its early stages of settlement were drawn from within these ranks. By mid-1976, these students had been joined by the first refugees from Pol Pot's Cambodia, increasing the community to some 500 people. From 1975 to 1986, 12,813 Cambodians were settled in Australia under the Refugee and Special Humanitarian Program. In the late 1980s and early 1990s, a small wave of 315 Cambodian asylum seekers arrived by boat on Australian shores. These refugees were put in immigration detention centres, in some cases for several years, and encouraged to return to Cambodia and apply for resettlement in Australia through the proper channels. During the January 1994 Australia Day celebrations attended by Prince Charles, a troubled Cambodian Australian youth, David Kang, leapt onto the stage and fired a starter pistol into the air in protest against the lengthy detention of the Cambodian boat people. Today, Cambodians continue to arrive in small numbers in Australia under the humanitarian and family reunion categories.

As the first Khmer refugees began to arrive in 1975, a community organisation called The Khmer Community of New South Wales was formed, with the objective of providing settlement services to newly arrived Cambodians. Most of these arrivals settled in the Fairfield and Liverpool local government areas, near the migrant hostels where they had lived after arriving in Australia. In the mid-1980s, the Venerable Long Sakkhone, a Cambodian Buddhist monk, came to live in Sydney. Frank Walker, New South Wales Minister for Housing, arranged for the lease of a tract of land next to a large shopping plaza at Bonnyrigg, to the Khmer Community of New South Wales for the purpose of constructing a community centre and temple. It was officially opened by the Premier of New South Wales, Nick Greiner, on 10 February 1990. The tall and ornate sala of Wat 
Khemarangsaram is an imposing structure amid the suburban Australian setting of Bonnyrigg, with its gum trees and red brick houses. It is an important focus of community life and a source of pride for Khmer Australians, who funded this building largely on their own. On the weekend of the Theravada Buddhist New Year, which falls near Easter, the temple is host to rituals, a food fair, and musical performances by singers from Cambodia. The event is well attended by both Cambodian and non-Cambodian Australians.

\section{Community identity}

In Australia, roughly a third of those of Cambodian birth are ethnic Chinese. This reflects the composition of the population of Phnom Penh, which was one-third Chinese in the $1960 \mathrm{~s}^{2}$ and most likely remained so until the mid-1970s. Many ethnic Chinese Cambodians in pre-Pol Pot Cambodia were involved in small business and trading, and many Sino-Khmers have continued this tradition in Sydney. Ethnic Chinese Cambodians in Sydney run businesses including gold and jewellery shops, fabric and hardware stores, restaurants, groceries and bakeries. While there is a separate Cambodian Chinese community association, there is no strict division between the communities, and people of Chinese origin participate in Cambodian Australian community life alongside ethnic Khmers, some holding important positions within the community. Some Chinese Cambodian Buddhists celebrate both Mahayana and Theravada Buddhist festivals, and attend both types of temples.

Another important sub-community within the Cambodian one in Sydney is the Khmer Kampuchea Krom community. The 2006 census shows 466 people of Khmer ancestry born in Vietnam who are resident in Australia, of whom 174 live in Sydney. The term Kampuchea Krom or 'Lower Cambodia' refers to the Mekong Delta region of Vietnam, an area that used to be part of the Khmer Kingdom but was progressively annexed by the Vietnamese, a process that went on until the eve of French colonialism in Indochina in the mid-nineteenth century. The Mekong Delta provinces of Vietnam are home to a large number of ethnic Khmers, the majority of whom still live in traditional villages surrounding Theravada Buddhist temples. Khmer Krom in Australia identify closely with the Cambodian community, but also form a sub-community that has its own cultural and political characteristics. Many Khmer Krom are highly committed to the protection of the cultural and religious rights of the Khmer in Vietnam and very politically active in this cause. There are two Khmer Krom temples in western Sydney, also patronised by other Khmers, which have strong links with Khmer Krom temples in Cambodia.

A small percentage of Cambodia-born Australians are of Vietnamese ancestry, reflecting the history of migration from Vietnam to Cambodia.

\section{Occupations}

There are a number of Cambodian Australian professionals, managers and people with technical qualifications. In general however the Cambodian Australian community is a working-class one, with lower rates of educational qualifications than the general Australian population (13 per cent 
compared to a national average of 58 per cent), and higher participation in semi-skilled and unskilled occupations (43 per cent are labourers and machinery operators compared to a national average of 8.8 per cent). Cambodian Australians are known for their association with insulation and sheet metal-working in the power and mining industries. According to the 2006 census the unemployment rate for the Cambodian Australian community was 12 per cent, compared to a national rate of 4.4 per cent. $^{3}$

\section{Ties to homeland}

Since the United Nations Transitional Authority Cambodia (UNTAC) mission in 1993, Cambodia has notionally been a multi-party democracy. This means that, unlike the Vietnamese and Lao communities, Cambodian Australians can be actively involved in electoral politics in Cambodia.

Initially the great majority of Cambodian Australians supported FUNCINPEC, Cambodia's royalist party, which won the elections held under UNTAC but was prevented from taking power by Hun Sen's Cambodian People's Party (CPP). Many associate the CPP with the Vietnamese occupation and ongoing Vietnamese influence in Cambodia, and it remains unpopular in the diaspora. However, a number of Cambodian Australians have returned to Cambodia to work with the party. Most notable here is Ung Huot, from Melbourne, who became for a short time the FUNCINPEC co-Prime Minister with Hun Sen after the coup against Norodom Ranariddh in 1997. Savath Pou, who lives in Sydney, was for a time a senator in the Cambodian government and head of the CPP's representative offices overseas.

In the diaspora, FUNCINPEC and the Sam Rainsy Party retain some support. However many overseas Khmers have grown disillusioned at the opposition's failure to make any significant progress, and have consequently become disconnected from Cambodian politics. Overseas Khmer have as yet no right to vote in Cambodian elections, but some have made calls to be given this right, as neighbouring Thais already have. Many Cambodians have ongoing concerns about the weakness of Cambodian sovereignty and believe that the country's land and natural resources are being expropriated by neighbouring Vietnam and Thailand.

Cambodians in Australia maintain an important connection with their homeland. However, because of the catastrophic nature of the Khmer Rouge period, many refugees lost their entire families, and have few if any close relatives left in Cambodia. Many of those who survived the Pol Pot era have distanced themselves from Cambodia, as returning there is a painful and even traumatic experience, or because they feel they have no one there to go back to. The social dislocations of the Democratic Kampuchea period were such that it is a common experience for Cambodians to return to their old village or home town and find no one familiar there. The corruption and social injustice that are endemic in Cambodia also tend to make Cambodians overseas feel that it is a place without hope. Khmer Australians in general visit their homeland less frequently than their Vietnamese counterparts. 


\section{Religion}

Cambodian Australians are overwhelmingly Buddhist, with a few hundred Christians, many of whom were converted by missionaries in the refugee camps in Thailand. Theravada Buddhism, Cambodia's national religion, is the community's main faith. In Theravada Buddhist practice, the community cares for the monks by making ritualised food offerings or dak baat. Monks from Wat Khemarangsaram make twice weekly outings with their begging bowls to Khmer households in Bonnyrigg and to Cabramatta shopping centre to perform dak baat. Elderly devotees live at the temple to prepare food for the monks on a daily basis.

Wat Khemarangsaram holds a weekly holy day (thnai sel), involving a sermon and chanting. During the Rains Retreat (Vassa), a three month period corresponding with the rainy season in Cambodia, the monks chant and meditate daily. At other times, they leave the temple to perform various rituals for the community, most importantly at deaths, wakes, funerals and one month birth anniversaries. The monks may attend hospital to perform rites immediately after a community member has passed away. The body of the deceased may also be kept overnight at the temple before going to the cemetery.

Most importantly, however, temples are the site for the celebration of festivals. The most significant of these is New Year (jo chnam thmei or Songkraan). Other significant ceremonies include Pchum Ben, a 15-day period during the Rains Retreat in which families perform rituals and offer food for the souls of their ancestors, and Vesak Day (Visak Boja) or Buddha's birth celebrations. Other important ceremonies mark the beginning and end of the Rains Retreat, and Kathen or the offering of new robes to monks following the end of the rains.

\section{Community organisations}

The Cambodian Australian community has no overarching community organisation, but rather a number of small organisations with different but overlapping constituencies. The two most important community associations are the Cambodian Awareness and Welfare Council and the Khmer Community of New South Wales Inc. These are the only two organisations that receive government funding and employ full-time case workers. Both provide settlement and welfare services. There is also a Khmer Kampuchea Krom Community of New South Wales organisation. ${ }^{4}$

Sydney's Cambodian temples all have temple associations, which oversee issues such as recruiting monks from Cambodia, building and maintenance on temple grounds and, most importantly, organising festivals. There is also a Cambodian Christian Community of New South Wales.

Khmer language associations include Bonnyrigg Khmer Language School (based in Bonnyrigg Public School), Khmer Adventist Language School (based at Adventist Church, Broomfield Street, Cabramatta), and Links To Learning Program (based at Cabramatta West Public School). 
A Khmer Growers Association of New South Wales represents the interests of Khmer Australian market gardeners in western Sydney. Finally, the Khmer Youth Association of New South Wales Inc serves the needs of Khmer youths.

\section{Media and entertainment}

Many Cambodian people rely on radio for information about events happening in both Cambodia and Australia. There are at least three major radio stations to which Cambodians listen: SBS Khmer radio; the Community Radio Program on 2GLF 89.3 FM (attached to the Khmer Community of New South Wales); and the Ethnic Radio Program, 99.9FM. Radio Free Asia Khmer and BBC Khmer are also popular broadcasters, accessed through the internet.

A small number of Cambodian families are able to afford satellite TV to keep up to date with what happens in Cambodia, and view entertainment from their homeland. The Cambodia-based TV networks that broadcast through satellite are CTN (private) and TVK (state). Thai soap operas and movies dubbed into Khmer are also extremely popular, especially among older members of the community.

Many Cambodian people also buy Khmer-language magazines published in Cambodia. The most widely read Khmer-language magazine is called Popular Magazine.

There used to be a Khmer-language newspaper called Smaredey Khmer. This newspaper ceased publication before 2005 due to insufficient demand.

Ashley Carruthers is a lecturer in the School of Archaeology and Anthropology at the Australian National University in Canberra

Sarithya Tuy is Community Development Worker, Economic and Safety Development, New Leaf Communities

\section{References}

J Coughlan, 'Cambodians in Australia: A Brief Statistical Overview', unpublished manuscript, 1994

Richard Lunn, Leaving Year Zero: Stories of Surviving Pol Pot's Cambodia, University of Western Australia Press, Perth, 2004

Alice Pung, Unpolished Gem, Black Inc, Melbourne, 2006

Alice Pung (ed), Growing Up Asian in Australia, Black Inc, Melbourne, 2008

\section{Endnotes}

${ }^{1}$ Australian Bureau of Statistics, 'Ancestry (Multi-response) by Country of Birth by Language Spoken at Home by Sex', based on 2006 census, special table commissioned by authors

${ }^{2}$ WE Willmott, The Political Structure of the Chinese Community in Cambodia, Athlone Press, London, 1970, p 1 


\section{Endnotes}

${ }^{3}$ Australian Bureau of Statistics, 'Ancestry (Multi-response) by Country of Birth by Occupation (ANZSCO2006) by Sex', based on 2006 census, special table commissioned by authors

${ }^{4}$ Khmer Community Directory website, http://www.communilink.org.au/Communities/941/Khmer_Directory.asp, viewed 15 January 2009; Cambodian-Australian Welfare Council of New South Wales website, http://www.cambodianwelfare.org.au/, viewed 15 January 2009; Khmers Kampuchea Krom Federation, http://www.khmerkrom.org/en/culture.php, viewed 15 January 2009 